\title{
The Big Challenge: Teaching Large Multi-Level Classes
}

\author{
Nevila Treko \\ E-mail: nevilatreko@yahoo.com
}

\section{Doi:10.5901/ajis.2012.v2n4p243}

\begin{abstract}
:
There are different kinds of classes in our school system. The majority of them are large multilevel classes. The world of the multilevel classroom, despite being an exciting, challenging and richly rewarding one for teachers, is by no means an easy environment, particularly for those entering it for the first time. This paper is intended to provide a particular guide for teachers facing mixed-level classes. It sheds light to the factors which bring to the development of a multilevel classroom and tend to explain the advantages and challenges of these types of classes. It also gives suggestions to the teachers for an appropriate classroom management and shows them some ways how to cope with evaluation and assessment in those types of classes. It also discusses the ways in which an instructor can create a productive learning environment in countries where there are limited resources for teaching.
\end{abstract}

Key words: teaching, learning, ELT.

\section{Introduction}

Teaching large English language classes to non-native learners presents many challenges throughout the world. These challenges can be impacted by the fact that more often than not, the classes are multilevel as well. Moreover, often there is also the added problem of inadequate resources or no supplies of any kind. Despite these challenges, meaningful learning can and does take place. This paper will discuss the ways in which an instructor can create a productive learning environment in a large multilevel classroom setting. These suggestions come from Baker \& Westrup (2000), Hess (2001), Renaud, Tannebaum, \& Standal (2007) and my personal experience as well in teaching large multilevel classes.

\section{- What does it mean to teach in a large multilevel class?}

First of all, what a teacher should be aware of is: - "what does it means to teach in a large class?". Hess (2001) defines a large class as thirty or more in her book. Ur (1996) suggests that 40-50 students constitute a large class. However, Baker and Westrup (2002) provide a useful definition by stating that: "a large class can be any number of students, if the teacher feels there are too many students for them all to make progress."

Adding to these types of classes even the multilevel factor; means that we have to focus not only in the large number of students but also on the variation in the students' control of language. As Karshen, Stephen.D \& Terrell, Tracy (2002) point out, we talk about the fluent student sitting next to the one who can barely piece together a sentence.

According to Taylor Marcia (2005) some factors teachers have to consider in these types of classes are:

Student's previous experience with education- variance in educational background means that some students have more experience in English classes so the teacher is likely to find that such students are ready and eager to move on to new material while other students are still struggling.

Learners' expectations of appropriate classroom activities- in this case the teacher have to make clear beforehand the classroom activities they are going to deal with.

Individual student's personality- the teacher should not forget the importance of individual factors such as intelligence and motivation. 
Learning style preference- Knowing a person's learning style such as:

Diverging (feeling and watching) - These students prefer to watch rather than do.

Assimilating (watching and thinking) - These students require good clear explanation rather than practical opportunity.

Converging (doing and thinking) - They can solve problems and make decisions by finding solutions to questions.

Accommodating (doing and feeling) - They commonly learn by instinct rather than logical analysis, enables the teacher to deliberately use a variety of methods to reach the students' needs.

Multilevel classes are offered for a variety of reasons. Some of these classes have been roughly created according to age group. In areas with few students mixed level classes may be the only option. Also, few schools can afford to provide teachers at all levels of instruction when there may be only three or four students enrolling in each category. Companionship and support, however, tend to explain why students tolerate mixed level classes rather than why they seek them out. According to Ronald H. Heck, Scot Lorign Thomas (2008), in fact many students prefer mixed level classes, generally because they have friends or are shy and enjoy the moral support of a friend.

\section{- Advantages and challenges}

The teacher should also take into consideration the advantages and challenges which are going to face in teaching these types of classes, in order to make use of them to fulfil the educational goals.

Perhaps, it is honest to suggest that there are more challenges than benefits to teaching large multilevel classes. For example, many teachers feel out of control in such an environment. In addition, many teachers also feel trapped in the problems of management; keeping students on task and speaking in English. Then there is the difficulty of providing for individual learning styles. It can also be difficult to motivate and activate quiet students in a large group setting. There can be occasions where teachers can be frustrated by the huge amount of written work. As mentioned earlier, there is also the problem of teaching with limited resources in many countries. However, these challenges are not insurmountable; there are several strategies for coping with such issues.

Facing all these problems sometimes is hard to believe that there are any advantages to multilevel class, but in fact there are some.

One of the most common advantages is that the teacher is unlikely to be forced into teaching a set syllabus. Second the variety of background knowledge leads to interesting differences in view point and experience, so that natural interactions are possible between students. As Ur (1996) points out there are also advantages for the individual student. Beginners have the opportunity to call on a wide range of advanced peers as helpers rather than relying solely on the teacher while the advanced students get the satisfaction of demonstrating their power.

\section{- Management skills required}

Teaching of multilevel classes demands from the teacher good management skills.

The teacher would do well first to build up a sense of group feeling within the whole class before breaking the students into groups and also ensure that a variety of small groupings are used, not merely a rigid split among ability lines but depending on the task at hand.

It is important for a teacher to encourage the students' responsibility in their process of learning. Students must come to realize that new behaviours will be demanded of them. They will be asked to get up out of their chairs and work different situations. They will be asked to work with students of different abilities. They will be asked to perform tasks that can only be completed with an exchange of information. They will be asked to solve problems. Students will be asked to decide for themselves what they want to learn and how hard they want to work at it. They have to make their own decisions of what they want to learn. 
Students will progress more quickly in their learning if the teacher can relinquish the traditional "leader of the class" role and instead adopt that of advisor and facilitator.

Group work is an important element which requires the teacher management ability for achieving good results. The size of a group varies considerably, depending on the task at hand and also by the number of students in a class. It makes the members of the group interact and communicate with each other. The goal is for students to participate in a conversation, to swap information back and forth, to share knowledge, and to argue out strategies. It is up to the teacher to decide the group types he/she wants to use in different class activities.

As Taylor, Marcia (2005) points out there are different kinds of group working:

- Fixed groups have some advantages, the main one being that you can save a lot of time in getting groups organized and started on a task. Groups members get to know each other quickly and build a strong sense of group identity. While there are also some disadvantages. The main one is that patterns of dominance and leadership tend to develop within the group. Another problem comes when irregular attendance destroys the personality balance in a group.

- Multiple groups consist to the compromise of different group combinations with which the students are familiar, so that they regard themselves as belonging to one of three or four different combinations.

Teachers should be aware that classes that have never worked in groups may display some resistance to the idea at first but they soon get used of it.

\section{- Activities}

Many activities which require group work are available to a multilevel class. There are activities for equal ability groups, for cross ability groups, for pairs and for individuals. Obviously, this can be a planning nightmare and a lot of extra work is required from the ESL teacher. But apart that the good news according to Miriam Burt and Mark Saccomano (2005) is, that even extreme differences in language levels can be successfully managed so that all the students will progress in their language learning. Wise teachers will not rely exclusively on any one pattern but will call on all of them according to which is best for the skill being practiced.

The most frequent ones are:

\section{ESL Multilevel Activity 1 - Whole group Warm-up:}

Starting class with a whole-group warm-up is a great way to foster a sense of community in a multi-level class. There are a variety of warm-up activities to get students focused on English at the beginning of a class that can be incorporated into a routine. Some warm up activities include: songs, games (hangman, telephone, bingo, etc.), quizzes, and discussion questions. Reviewing material is also a common warm up activity. Recycling and reinforcement is important in large multilevel classes and doing this at the beginning of class can reinforce concepts learned in previous lessons. Some examples include: expansion activities, answers to questions, making review posters, review of learned vocabulary (for example: person/place/thing).

\section{ESL Multilevel Activity 2- Information gap exercises:}

Works great for cross-ability pairs.

\section{ESL Multilevel Activity 3- Crossword puzzles:}

Works well for cross-ability pairs. Despite their English vocabulary levels, each student will bring a wide variety of knowledge to the group to help fill in the puzzle. 


\section{ESL Multilevel Activity 4- Folktales:}

It is easy to find different levels of common folk or fairytales. These work well in children's classes, and there are even some that are appropriate for adults. If teachers have difficulty in finding a folktale that is a suitable level, they can always rewrite one themselves and use it again and again when they are teaching. The follow up activities for folktales are unlimited, but include comprehension questions, group discussions, vocabulary activities, creative writing exercise, and role-playing, all of which can be done in various groupings.

\section{ESL Multilevel Activity 5- Art and images:}

Visual stimuli can be a great teaching tool. Use paintings as the basis for class discussions, writing assignments, and vocabulary building. Students of all different levels can participate together by describing photographs. Encourage students to bring in their own pictures and art and find ways to build lessons around them. One great pair activity that acts as a listening and speaking activity is to put students in pairs and have one of them describe a picture while the other tries to draw it. This can also be done as a whole group. The students can choose a photo and describe it to the instructor or another student who will try to reproduce it on the board.

\section{ESL Multilevel Activity 5 - Buddy Reading}

For writing and reading, students pair up for buddy reading, and peer editing. Buddy reading involves one student reading and the "buddy" helping to make sure that the reader is pronouncing the words correctly. The buddy also asks questions after the reading to check comprehension.

The teacher is required to model this for the group first, but with adults it is often considered to be a very easy multilevel activity to pick up since it is similar to studying together outside of class. Higher level students are able to monitor lower level students, and interestingly, having lower level students monitoring higher level students often works to help the higher level students become more aware of fossilized errors that they are making.

\section{ESL Multilevel Activity 6- Peer Editing}

Similarly, peer editing allows students to look at each other's work and make corrections and comments at their own levels. Pre-writing and rough drafts can be done independently. Advanced ESL students can be encouraged to write more and with greater grammatical complexity. Peer editing is then done as a last step before writing the final draft. Students can be encouraged to discuss content as well as grammar and punctuation.

Games are, of course, the ultimate ESL multilevel activity. The beauty of games is that they are generally excellent for encouraging meaningful interaction between students even with very different levels of English. By taking time to pre-teach any necessary vocabulary and grammar, all students will be able to participate in the games together. Examples of multilevel ESL games that work well are Jigsaw Reading, Name the Thing, and How It's Made - these ESL games and more are all in Hess (2001) book of games for teens and adults.

\section{ESL Multilevel Activity 7 - Jigsaw Reading}

Jigsaw reading is quick to prepare. The instructor simply selects a reading, pre-teach the vocabulary and grammar, preferably with games, and divide the reading into parts. Each student reads their part of the article or story silently to themselves. Advanced students should be given longer and more challenging passages, and lower level students the short, simpler parts. After reading, you can have the student either write a 
summary of the article or story, or give it orally. Finally, working together, the students try to reconstruct the article in the correct order, and check it against the original article.

\section{ESL Multilevel Activity 8 - Name the Thing}

Name the Thing requires picture cards. The teacher should make the students work in pairs, and lay out for each pair a set of three or four pictures of similar, but not identical items, such as four similar cars. One person holds a matching picture of one of the items displayed on the table, and uses this as a reference for answering questions asked by the other students. These students ask questions to narrow down their choices and pick the correct matching picture. The more advanced students can do the questioning, as this is harder than coming up with answers. A tip for this game is to first demonstrate it at the front of the class and then ask students to each collect a set of pictures for the game to play at the next lesson. The teacher can then keep the best of those sets for future use.

All these games are included in the www.teachingenglishgames.com_for teens and adults with 163 games and activities!

\section{ESL Multilevel Activity 9 - How it's made}

How It's Made simply requires directions on assembling something. It is always fun to do peanut butter sandwiches or some other simple food, and actually bring in the ingredients to practice with. Each student is given one step in the process, and they must discuss their step with the others and decide where they fit in. It can also be done with blocks or a simple puzzle or model Lego. The instructor should give the more advanced students more steps and/or more complex instructions. The beginners have something simple, like putting the wheels on the Lego car.

How it's Made Variant: Another way to play this if you have no instructions to hand is to simply have a rule where a student cannot move any piece without saying something. If a student wants to pick up a piece off the table and try it to see if it fits on the model or in the puzzle, or stick it with another piece, he or she MUST say something in English.

For example, using a puzzle with a picture that includes some red flowers: advanced students give a running commentary of their actions, "I'm just going to see if this small red piece fits on here... it looks like it might be part of a flower. Oh no, it doesn't fit". Whereas a beginner might say, "I think this is a flower", or "it fits/it doesn't fit". Alternatively you can have students practice and repeat any kind of sentence or grammar that you are learning, and it does not have to be related to the theme of the puzzle or model at all. So a beginner could say "I like pears" and this will give them the right to try a piece on the model or puzzle. If working with several groups they can race each other to see who finishes first.

\section{- Strategies}

Also, there are a number of strategies for coping with large, multilevel classes. Some of these are general strategies that instructors can incorporate into their teaching routines. Other strategies inform syllabus writing or planning/materials development in that they will help motivate and activate language use in the classroom.

\section{Routines}

One of the basic strategies for coping with large multilevel classes involves setting up routines. This can include things like creating a seating chart and strategies for taking attendance, writing the day's activities on the board, posting deadlines in a visible place, or starting the day with a warm up activity among other considerations. Some other considerations include having established groups in advance for group work and establishing quiet signals to show students when to start and stop activities. 
Perhaps, the first and most important coping strategy involves knowing student names. There are several reasons for this and the most basic is to create human

relations and to promote a comfortable atmosphere where everyone knows each other and feels comfortable sharing and experimenting in front of one another. Also knowing names can be helpful in the administrative sense by keeping attendance and keeping track of grades. Knowing names is also useful for class management in that you can single out students who are not using English or not on task by name.

There are a variety of methods for learning student names including the use of seating charts, name placards, ice breaking activities (like "Find someone who..."), student introductions, and name games (like "I am and I love..." or "Names and adjectives").

\section{Student Motivation and Activation}

Another effective strategy for coping involves motivating students to learn and activating usage of English in the classroom. There are several effective strategies for student motivation and activation. However, Hess (2001) points out that there are a few important things to remember: it is not necessary to hear everything said or read everything written, students should talk about real issues of importance to them, and there should be activities with many choices of expression. Some suggested topics and themes that might be of interest to students include: People I Admire/Special Places/Dreams I Have/How I Feel Now/Friendship/Favorite Things/Shopping/Travel/Eating Out/Careers/Movies.

There are a number of strategies in classroom instruction and curriculum planning that can enhance lessons for large multilevel groups and promote motivation. One area is using a variety of classroom activities. This can be effective for motivation and activation, for example, by mixing activities like lectures, small group work and pair work. Pace is another important consideration when addressing student motivation and activation. It is useful to make provisions for students who finish early and create activities for students who require extra time. Also, it is important to consider individualization, which allows for personalization, choice, and open ended that can inspire motivation and lead to activation. Ur (1996) describes individualization as a situation in which learners are given freedom to choose what they learn and adopt or select tasks and materials, which suit them as individuals. (p.233). this means creating opportunities for students to work on projects of interest to them as well as chances to exercise language at their own level of competence.

\section{Suggestions for Teaching Writing}

There are a number of approaches that can make teaching writing to large multilevel groups easier and more effective. Writing can be taught together with other skills, but if the course is a writing course, it is usually most effective when employing the writing cycle. The first stage in the writing cycle is the pre-writing stage to decide upon a topic. This involves techniques like brainstorming, clustering, and lists. After the topic has been decided the next steps are writing a thesis followed by an outline.

Once these have been decided the students write a first draft. Peer editing is an essential part of the writing cycle and students can edit each other's first drafts. One approach can require students to have one self-edit and two peer edits before teacher evaluates the final draft: this would suggest that the first and second drafts would have peer edits for content and technical aspects of writing with one final self-edit before handing in the final draft for evaluation. In the event that a large portion of the students are low level it can be useful to give students examples of common writing errors in regards to style, usage, spelling, or grammar then edit for those examples. For example, if the students are having trouble with subject and verb agreement, a mini-lesson with examples before editing will help students identify errors in their individual writing and that of their classmates. The writing cycle can include a portfolio of student drafts to bring to writing conferences in order to get meaningful feedback, but the peer editing should also provide meaningful feedback. 


\section{- Assessment}

Heide Spruck Wrigley (2006) points out that it is quite common these days to hear of multilevel teachers being forced to use standardized assessment procedures with their students. Other teachers report that, although they are spared external tests, they are required to produce detailed learning plans and regular individual assessment for every student, even though they only see two or three hours a week in a group setting. Both these extremes are problematic. No externally developed standardized test can do justice to the range of skills that are evident in most multilevel classrooms. However, few multilevel teachers have sufficient access time to carry out lengthy individual assessments, without neglecting other students in the process. So what is the best way to assess the multilevel students?

There is no easy or perfect answer to this question. The best one is to identify or develop acceptable assessment tools that address the needs of learners, but that can also be incorporated into our regular classroom work.

For many of us, our first reaction to the question of what we are trying to assess is to think in terms of testing students' language competence, but in fact our assessment activities need to look at a much wider range of issues. Of course we need to find out what students can do, but its' also important to find out what they want to do, and whether they are making acceptable progress towards those goals. We also need to assess ourselves. What's our teaching like? Would the students prefer us to change something in our daily teaching? How about the materials we use? The grouping patterns we push them into? Is the location and timing suitable? According to Heide Spruck Wrigley, (2006), as far as our students are concerned, therefore, we have two key evaluation components- initial assessment for needs analysis and on-going assessment to ensure progress.

The students' need compares what the learners can already do with what the learners need to know in order to operate satisfactorily. Before determining the needs of language learners, we must ask some questions (e.g.: age, background knowledge, purpose of learning, what they want to learn, what socio-cultural knowledge the learners lack etc.). Once the students' needs are identified, the question arises as to how progress will be measured. Before making on-going assessment, we need to have a sense of the students' starting point, so it is important that we record or preserve any assessment that we conduct at the beginning of the year. The simplest option according to Karshen, Stephen D \& Terell, Tracy (2002) might seem to be to have a standard test designed by experts. At various points during the program, the students can retake the test and their improved scores will be a good indicator of their progress. But there are a number of drawbacks to such tests. The first problem is simply the difficulty of finding an acceptable test. The problem for the multilevel class is that any test that allows for our stronger students to display their full range of competence will be overwhelming for those learners "still struggling with the alphabet'. Standardized tests do not tell us whether the individual can produce the language in a real- life situation, nor do they tell anything about the socio- cultural knowledge. However, many teachers would use them.

As Heide Spruck Wrigley (2006) points out, most experienced classroom teachers instinctively observe student behaviour and language use. As we present an activity, we watch to see who gets on with the task immediately and who takes time to settle down. We note which combinations of students work well, and which are problematic. In order to make it easy we can use the benchmark chart.

The students own assessment is another critical component of the overall evaluation. They can tell you whether the skills they have learned in the classroom work outside in real life, something no examination or test can. Self-assessment can take many forms. At a very simple level, the teacher might produce a short form that lists activities done during the week, and ask the students to indicate whether they found the work easy, moderate or difficult. At different stages, perhaps monthly, the process is repeated.

Any such self-assessment should be placed into the student's portfolio. Portfolios are very useful tool for on-going student assessment because they demonstrate the growth a student has made over time. Assessing the variety of activities that take place each day is undoubtedly more difficult in the multilevel classroom than in a more homogenous class. The consolation is that, no matter how variable the rates of 
progress, there will be activities suitable for each student. Only in a class like this can students truly work at pace.

\section{- $\quad$ Teaching large multilevel classes with Limited Resources}

As mentioned earlier, many teachers from different countries have the added burden of a lack of resources. This could mean no textbooks, no access to photocopiers, little access to books, or no electricity. Renard, et al. (2007) suggest an alternative to writing notes on the board is for students to copy as the teacher dictates the information using dictogloss He does not suggest that this activity be used instead of writing notes on the board exclusively, but rather as a supplemental activity to use on occasion. This is a method where students listen to a passage twice read at normal speed, taking notes during the second reading. Then students work with a partner to try and reassemble the text. Once the pair thinks that they have the correct reconstruction they write the section on the board and the whole class work together to recreate the original as much as possible. Then the teacher makes the final corrections. In order to save time during class, teachers can write texts or questions on large sheets of paper before class rather than writing on the board. If the class is especially big, then two or three copies can be made. Teachers can also ask students to bring an item from home to use as a talking or writing point for the class. Another suggestion is using pictures from magazines or drawn to illustrate vocabulary or create interest in reading, speaking, or writing activities. Use what the students say themselves as the input. This can be done by having student change direct speech into indirect speech, having the a student ask a question and then have another report orally or in writing what the student said, or students can make statements on topics provided by the teacher and the rest of the class writes it down as student-centered dictation.

\section{Conclusion}

No two classes are alike as Ur (1996) points out, so the ideas that work well for a teacher may not work the same way for another one. The teacher is the one who knows his/her own classes best, and the one to decide exactly how things should be done in his/her own classrooms. There are not perfect recipes especially in teaching multilevel classes but knowing the advantages of it will remind the teacher that there are some pluses in this setting, and knowing some of the activities and different ways of grouping the students in these types of classes will help them manage it better. Also making students participate not only in the learning process but also in evaluation and assessment of their own development will be helpful for both of them. Of course every teacher would like to have a class of less than 10 students with all the latest access to technology. However, that is a far cry from what many teachers throughout the world have to cope with every day. But this does not mean that they cannot effectively teach large multilevel groups. And it is the individual teacher's role that is effective in determining the rate of language acquisition and learning in the classroom. If the teacher is open to reorganizing the classroom and allowing more activities, then the student will be in a better position to learn. The coping strategies that focus on routines, motivation and activation, and teaching writing offer some possibilities for incorporating new ideas in the classroom. The final section related to teaching with limited resources suggests ways to do more with less. There are always ways to make learning more fun, easier for the teacher and students, so it is important to keep looking for better more effective ways of instruction. These are some of the ideas treated in my theme. I hope for them to be helpful and useful for all of us in our developing carriers as foreign language teachers in order to better reach and achieve our main goal.

\section{References}

Baker, J., \& Westrup, H. (2000). The English teacher's handbook: How to teach large classes with few resources. London: Continuum.

Heide Spruck Wrigley, Oxford, England (2006) " Learner Assessment in ESL Instuction".162, 78,122 
Hess, N. (2001). "Teaching large multilevel classes". Cambridge: Cambridge University Press.

Karshen, Stephen.D \& Terrell, Tracy. Toronto C.A (2002) " The natural approach: Language Acquisition in the classroom", 78, 123

Miriam Burt and Mark Saccomano, (2005) "Evaluating Workplace ESL Instructional Programs". 96

Renaud, S., Tannebaum, E., \& Standal, P. (2007). 'Student-cantered teaching in large classes with limited resources. English Teaching Forum, 45(3), 12-18.

Ron, H. Heck, Scot Lorign Thomas, Detroit, US, August (2008) "An Introduction to Multilevel Modelling Techniques". 98 Taylor Marcia, Washington D.C (2005) "The Language Experience of Approach and Adult Learners" .134- 203

Ur, P. (1996). A course in language teaching

www.teachingenglishgames.com 
